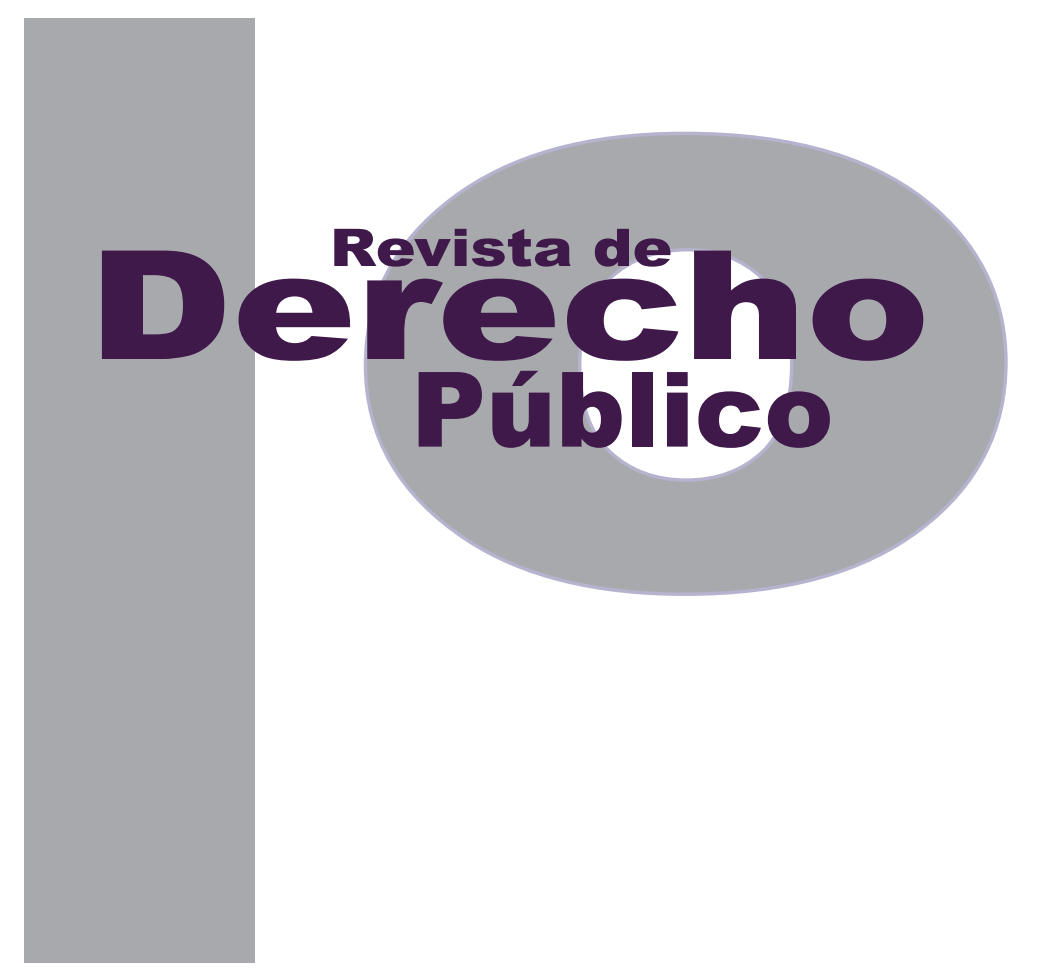

\title{
EN OCASIÓN DEL DÉCIMO ANIVERSARIO DE LA SUSTENTACIÓN DE LA TESIS DOCTORAL DE M. DIDIER BODEN
}

\author{
Universidad de los Andes \\ Facultad de Derecho \\ Revista de Derecho Público N. ${ }^{\circ} 28$ \\ Enero - Junio de 2012. ISSN 1909-7778
}




\section{En ocasión del décimo aniversario de la sustentación de la tesis doctoral de M. Didier Boden}

Boden, Didier, L'ordre public : limite et condition de la tolérance. Recherches sur le pluralisme juridique [El orden público: límite y condición de la tolerancia. Investigaciones sobre el pluralismo jurídico], tesis, Université Paris 1 PanthéonSorbonne, 2002, dos vol., 993 pp., premio Dupin Aîné.

1.- El fenómeno de la ambigüedad y de la indeterminación se verifica no únicamente en el terreno del derecho, sino en toda clase de disciplinas científicas $\left({ }^{1}\right)$. La expresión "orden público" detenta así significados diversos y variados.

Ciertos órdenes jurídicos imponen efectos a normas que emanan de otro orden jurídico. Sin embargo, ante una condición determinada, el gran contraste que tal efecto jurídico provocaría con respecto al ordenamiento jurídico que acoge la regla provoca en ocasiones la consecuencia de su rechazo. De allí que el autor designe como "orden público, límite y condición de la tolerancia" a esta recepción de un orden jurídico por otro en el campo específico del orden público. ${ }^{(2)}$ Siguiendo el método francés, Boden encara la ardua tarea de descifrar su contenido en dos partes.

\footnotetext{
1 V. pp. $11-15$

2 V. p. 88
}

2.- La primera parte, intitulada "definición del orden público y de su imperatividad" trata fundamentalmente sobre los tres usos principales del orden público: el objeto de la policía administrativa general, el límite de la tolerancia de un orden jurídico hacia las normas de otro orden jurídico y la licitud de los actos jurídicos. Esto no quiere decir que el autor descuide las definiciones secundarias del orden público y de la imperatividad $\left({ }^{3}\right)$ incluso en materias no jurídicas que tocan tangencialmente la cuestión $\left({ }^{4}\right)$. Testimoniando de sus calidades científicas, el autor sobrepasa la exigencia de presentar a la comunidad académica nada menos que los 104 usos jurídicos del orden público. La conclusión principal aportada en este punto es la siguiente: Según la regla de la auto persuasión, según la cual la certitud de que una cosa existe es inver-

3 En el derecho del trabajo, v. pp. 107-114; en derecho procesal, v. pp. 115-144; el derecho transitorio, v. pp. 145-173; en el derecho penal internacional, v. pp. 194-204; en derecho fiscal internacional, v. pp. 205-210; en derecho administrativo internacional, v. pp. 211-214; en derecho internacional público general, v. pp. 231-233, 269-265 y 417437; en derecho constitucional, v. pp. 234-237; en derecho de los tratados, v. pp. 237-239; en materia de ius cogens, v. pp. 239-245, 247-249 y 438-446; con respecto al federalismo, v. pp. 245-246. En el derecho de los países europeos, v. pp. 276-301; en el derecho europeo, v. pp. $302-328$, pp. 372-376 donde el autor demuestra la existencia concreta de un orden público europeo y 377-406; en la articulación entre el derecho europeo y los derechos nacionales, v. pp. 329-350; en derecho comparado, v. pp. 351-358; en derecho penal interno, v. p. 360; en el campo de la historia del derecho en relación a la noción tomada del derecho privado del Antiguo Régimen, pp. 446-454 y con respecto al derecho de la ocupación, v. pp. 490.

4 En ciencia política (utilizado como sinónimo de régimen político, de ideología, incluso respecto a la guerra y la paz), v. pp. 214-230 y $407-$ 416; en materia religiosa "orden público religioso del Líbano", v. p. 454 nota $n^{\circ} 953$. 
samente proporcional a la intensidad de su apariencia, cuánto más visible sea el orden público menos visto será. $\left({ }^{5}\right)$ La literatura sobre el orden público está, dicho de otra manera, demasiado cargada de imprecisiones. La preocupación principal consistirá entonces en recuperar su rigor y mantener en sus justos límites la noción de orden público en el derecho internacional privado, evitando que sea invadida por las otras acepciones de la institución y permitiendo definirla por contraposición a la imperatividad. $\left({ }^{6}\right)$

3.- La segunda parte, intitulada “el orden público y la imperatividad en la teoría general del derecho en general y en la teoría del derecho internacional privado en particular" muestra que la idea de orden público pertenece a al contexto natural del pluralismo jurídico mientras que la de imperatividad al del monismo jurídico. El autor conduce su razonamiento interrogándose sobre qué es una teoría $\left({ }^{7}\right)$, cuál es su pertinencia $\left(^{8}\right)$ y sobre la diversidad discursiva de las teorías del derecho $\left({ }^{9}\right)$. Ello le permite detonar el núcleo de las discusiones sobre las teorías del derecho y las nociones de orden público y de imperatividad en el derecho internacional privado $\left({ }^{10}\right)$ para posteriormente interrogarse sobre los problemas que nacen a partir de la confron- tación entre el monismo y el pluralismo. $\left({ }^{11}\right)$ La demostración en este punto es que la oscuridad no reside en el derecho mismo sino en la descripción del derecho. “[...] nosotros podemos conceder que una modificación de los términos de la descripción del derecho nos parecería deseable. $\left({ }^{12}\right) "$

Posteriormente, el autor enfrenta la cuestión de saber si la ética debe presentar la tolerancia en términos monistas o pluralistas concluyendo que no hay ninguna duda que la excepción del orden público en el derecho internacional privado es el límite de la tolerancia activa como virtud interindividual y no el límite de la tolerancia como actitud del Estado.(13) El capítulo siguiente recupera el positivismo interrogándose sobre los razonamientos en derecho positivo tendientes a poner en práctica la excepción del orden público del derecho internacional privado $\left({ }^{14}\right)$ y sobre los razonamientos de derecho positivo tendientes a impedir la puesta en marcha de tal excepción. $\left({ }^{15}\right)$ Esta oposición simétrica desenreda las paradojas, problemas y círculos viciosos de la problemática estudiada y desemboca en la siguiente conclusión parcial: la confusión tiene su origen en las instituciones jurídicas que le hacen mención. $\left({ }^{16}\right)$
$5 \quad$ V. p. 466.

$6 \quad$ V. p. 503.

$7 \quad$ V. pp. $505-513$

$8 \quad$ V. pp. $514-516$

$9 \quad$ V. pp. 516-524.

10 V. pp. $524-544$

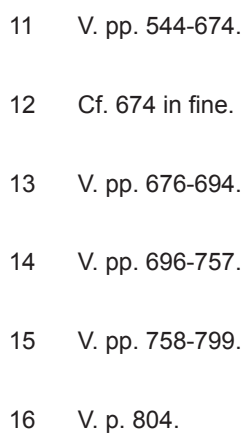

11 V. pp. $544-674$.

V. p. 804 
La conclusión general, en definitiva la tesis misma, es que las tres parejas compuestas por el orden público y la imperatividad, el pluralismo y el monismo, el unilateralismo y el bilateralismo componen una misma unidad coherente. Es debido a las diferencias entre los razonamientos normativos propios a cada campo dónde reside su irreductible antagonismo. $\left({ }^{17}\right)$

5.- Densidad, claridad, erudición, buen francés, originalidad, perspectiva, sobriedad; podríamos seguir rellenando estas páginas con formulas encomiásticas pero en suma, los aportes de esta tesis alcanzan dimensiones casi insuperables. Su vocación primera es el derecho internacional privado pero toca con profundidad y agudeza el derecho público, la teoría general del derecho, la filosofía jurídica, moral y deóntica, el derecho comparado, el derecho europeo y el derecho internacional general.
6.- En academias fuertemente divididas según la sensibilidad jurídica de cada pensador, BoDEN se abrió camino mostrando que las aproximaciones dialécticas son inútiles y que cada fenómeno jurídico puede ser descripto correctamente según el acercamiento más adecuado. No es de extrañar que esta obra haya sido laureada con un prestigioso premio doctoral y ello sorprende menos si consideramos que estamos en presencia de un egresado de Oxford, de la Sorbonne, de un ex investigador del Max Planck Institute con estudios efectuados en la Katholieke Universiteit Brussel y en I'Université de Liège, pero, por sobre toda las cosas, se trata de un jurista transparente cuya honestidad intelectual se inserta en los mejores valores de autenticidad y de veracidad.

De su lectura no podemos sino quedar impresionados y estarle profundamente agradecidos.

José Sebastián Kurlat Aimar

17 V.p. 814. 